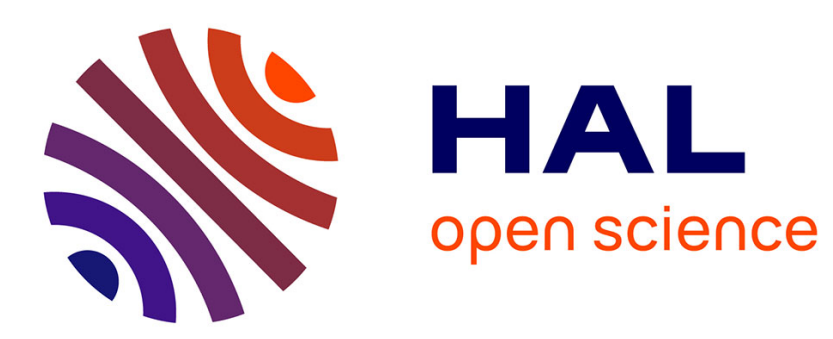

\title{
An Immersive Multitouch Workspace
}

Benoît Bossavit, Jean-Baptiste de La Rivière, Toni da Luz, Mathieu Courtois, Cédric Kervegant, Martin Hachet

\section{To cite this version:}

Benoît Bossavit, Jean-Baptiste de La Rivière, Toni da Luz, Mathieu Courtois, Cédric Kervegant, et al.. An Immersive Multitouch Workspace. Siggraph 2011 Emerging Technologies, Aug 2011, Vancouver, Canada. inria-00612507

\section{HAL Id: inria-00612507 https://hal.inria.fr/inria-00612507}

Submitted on 30 Aug 2011

HAL is a multi-disciplinary open access archive for the deposit and dissemination of scientific research documents, whether they are published or not. The documents may come from teaching and research institutions in France or abroad, or from public or private research centers.
L'archive ouverte pluridisciplinaire HAL, est destinée au dépôt et à la diffusion de documents scientifiques de niveau recherche, publiés ou non, émanant des établissements d'enseignement et de recherche français ou étrangers, des laboratoires publics ou privés. 


\title{
An Immersive Multitouch Workspace
}

\author{
Benoit Bossavit $^{1} \quad$ Jean-Baptiste de la Rivière ${ }^{2}$ Toni Da Luz ${ }^{2} \quad$ Mathieu Courtois $^{2} \quad$ Cédric Kervegant $^{2}$ \\ Martin Hachet ${ }^{1 \dagger}$ \\ ${ }^{1}$ INRIA Bordeaux $\quad{ }^{2}$ Immersion SAS
}

\section{Introduction}

Multitouch interaction has some unique strengths, one of them being that direct touch on 2D screens makes it fast and easy. Unfortunately, because of stereo disparity and content occlusion, direct touch interaction becomes an issue as soon as 3D stereoscopic content is visualized. We propose a new system that combines efficient direct multitouch interaction with co-located 3D stereoscopic visualization. In our approach, users benefit from well-known 2D metaphors and widgets displayed on a monoscopic touchscreen while visualizing 3D objects floating above the surface at an optically correct distance (see Figure 1(a)).

\section{Setup}

Our system is composed of a 32" multitouch screen on which users visualize and interact with monoscopic content. The stereoscopic visualization is provided by a $3 \mathrm{D}$ screen that is hung upside-down at the top of the system, and that reflects on a semi transparent mirror located between the user's head and the multitouch screen. Hence, stereoscopic objects are perceived as if they were displayed above the hands, between the mirror and the touchscreen. Head tracking ensures that virtual objects are displayed from a correct point of view. By mapping the virtual stereoscopic volume to the physical space, we can then produce a rich and consistent interactive visualization space. With this setup, the user sees in the same space the floating 3D objects, their hands, and the data displayed on the touchscreen. Our system inherently provides relevant occlusions clues. Indeed, the stereoscopic objects appear above the user's hands, while the monoscopic content remains below. Contrary to standard immersive 3D systems that only rely on affecting the eyes convergence to simulate 3D objects depth, our proposal also takes advantage of the eye accommodation and its capability to focus at different depths.

\section{Interaction techniques}

The monoscopic touchscreen provides a direct multitouch interaction space. Consequently, we benefit from the large variety of multitouch interfaces that were previously designed for such interfaces. Users are therefore able to interact in a fast and easy way with the content beneath the fingers, as they would do with a standard touchscreen. We have also designed a special widget that takes advantage of our setup to support the manipulation of 3D objects floating above the surface (see Figure 1(b)). It is displayed on the touchscreen, below the 3D object. Dual-touch gestures on the central disk of this widget result in Rotation-Scale-Translate (RST) operations on a plane parallel to the touchscreen, while additionnal rotation as well as scaling widgets allow the control of the remaining degreesof-freedom. Hence, users are able to control 9 DOF (plus uniform scaling) of the manipulated 3D object. Moreover, bi-manual interaction allows the manipulation of two objects at the same time. Since the 3D object always remains above the user's fingers and directly reacts to any motion of the control disk located below, this

\footnotetext{
*e-mail:jb.delariviere@immersion.fr

†e-mail:Martin.Hachet@inria.fr
}

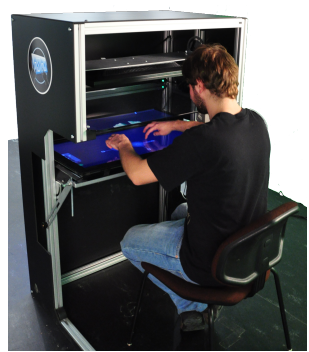

(a)

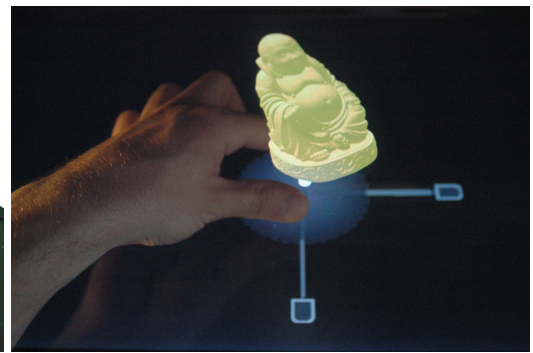

(b)
Figure 1: The setup and a 3D object being manipulated.

provides a near-direct interaction paradigm. Hence, users benefit from the advantages of both direct and indirect interaction.

\section{User Experience}

Such a setup combines immersive visualization and multitouch input within a seamless workspace, leading to specific strengths: fast and accurate interaction, easy 3D manipulation, immersive visualization, bimanual input, 2D system control, and so on. It provides a compelling experience to the user. We propose to focus our Siggraph demonstration on a virtual archeology reassembly experience, as such a task is a good example that illustrates the benefit of our setup. Attendees will indeed be able to browse through numerous 3D archaeological fragments and sort them out. To experiment with the solving of such a large puzzle, they will enjoy our occlusion free and head-tracked 3D visualization setup, and they will play with our specific multitouch widget to try different fragment combinations out. They will also enjoy bi-manual input. In addition to this scenario, we will also propose other demo applications to illustrate complementary use cases, in particular in the scope of architecture and medical visualization. The combination of multitouch paradigms and immersive visualization in a unified workspace opens new, unexplored, interfaces for interactive applications in these areas.

\section{Conclusion}

We propose to combine both multitouch input and immersive visualization into a single setup that relies on the strengths of each technology, while taking advantage of the specific capabilities that are introduced by a unique design. We believe the resulting proposal combines various research issues $(2 \mathrm{D} / 3 \mathrm{D}$ visualization, $2 \mathrm{D} / 3 \mathrm{D}$ interaction, immersion, direct and indirect multitouch input...), and it may inspire new usages. It will offer a new interactive and immersive experience to attendees and may contribute to push such technologies forward.

\section{Acknowledgments}

This work was supported by the ANR project ANR-09-CORD-013 InSTInCT - http://anr-instinct.cap-sciences.net. 